Check for updates

The BMJ

Cite this as: BMJ2021;373:n1089 http://dx.doi.org/10.1136/bmi.n1089 Published: 26 April 2021

\title{
Covid-19: Wider use of FFP3 masks may be needed because of airborne transmission, say scientific advisers
}

\section{Elisabeth Mahase}

Staff caring for patients with suspected or confirmed covid-19 may need higher grade protective masks-such as $\mathrm{FFP}_{3}$ masks-to protect them from contracting covid-19 through the air, according to the Scientific Advisory Group for Emergencies (SAGE). ${ }^{1}$

In a review carried out in March and published 23 April, SAGE said that while transmission of respiratory diseases are "conventionally classed as either airborne or droplet in a clinical context," current evidence suggests SARS-CoV-2 falls between these two categories with transmission "possible through inhalation and mucous membrane exposure to a range of particle sizes, as well as potentially through fomites."

Current guidance states that these high grade protective masks should only be worn in intensive care units or where certain aerosol generating procedures are carried out. ${ }^{2}$

Many healthcare workers and leaders have called for better protective gear, however, including in a letter in January 2021 which called for all staff working with confirmed or suspected covid-19 patients to be provided with $\mathrm{FFP}_{3}$ masks. ${ }^{3}$

SAGE has said that the decision to use $\mathrm{FFP}_{3}$ respirators should be based on a risk assessment that considers the interaction with a patient, the duration and proximity of exposure, whether there is good fitting and mask adherence, whether staff are routinely wearing eye protection, and whether patients wear masks.

Better air flow and dilution by opening windows or enhancing mechanical ventilation systems should also be considered when assessing need, said SAGE, though it also recognised that "applying full conventional airborne precautions throughout a hospital is neither practical nor likely to be necessary."

"Extending the use of $\mathrm{FFP}_{3}$ across care areas has operational implications; for example, it would require sufficient supplies of $\mathrm{FFP}_{3}$ to maintain stock and not compromise supplies for healthcare workers undertaking aerosol generating procedures who are at recognised increased risk," the review said. "If a decision were taken to enhance precautions in an area to include $\mathrm{FFP}_{3}$, then there needs also to be a clear strategy for how and under what circumstances the change would be stepped down."

BMA council chair Chaand Nagpaul welcomed the consideration of $\mathrm{FFP}_{3}$ masks as a "step in the right direction" and said it is "imperative that the government keeps to its promise to protect NHS staff as a priority."
"Healthcare workers shouldn't be faced with an unnecessary risk of contracting covid while caring for patients and far too many have become ill and even died as a result of becoming infected. The only way to ensure that the risk of avoidable transmission is reduced is to provide frontline workers with adequate protection. It's not a huge ask, but rather a lifesaving one," he said.

Nagpaul added that "robust research" was urgently needed to tackle the current evidence gaps in understanding transmission and protection.

When asked if the SAGE review would be acted on, a Department of Health and Social Care spokesperson told The BMJ, "The safety of NHS and social care staff has always been our top priority and we continue to work round the clock to deliver PPE that helps protect those on the frontline.

"Guidance on the appropriate levels and standards of PPE is written by experts and agreed by all four UK chief medical officers. Our guidance is kept under constant review based on the latest evidence."

\section{SAGE. Masks for healthcare workers to mitigate airborne transmission of SARS-CoV-2. 25 March 2021. www.gov.uk/government/publications/emg masks-for-healthcare-workers-to-mitigate-airborne-transmission-of-sars- cov-2-25-march-2021. \\ 2 Public Health England. Covid-19: guidance for maintaining services within health and care settings. 2020. https://assets.publishing.service.gov.uk/gov ernment/uploads/system/uploads/attachment_data/file/954690/Infec- tion_Prevention_and_ControL_Guidance_January_2021.pdf. \\ 3 Wise J. Covid-19: Doctors and nurses demand better PPE for wider range of procedures. BM/2021;372:n30. doi: 10.1136/bmi.n30 pmid: 33408072}

This article is made freely available for use in accordance with BM|'s website terms and conditions for the duration of the covid-19 pandemic or until otherwise determined by BMJ. You may use, download and print the article for any lawful, non-commercial purpose (including text and data mining) provided that all copyright notices and trade marks are retained. 